\title{
Assessing the cognitive status of older adults attending primary healthcare centers in Saudi Arabia using the Mini-Mental State Examination
}

Sulaiman A. Alshammari, MBBS, FRCGP, Adel A. Alhamdan, PhD, Saad M. Bindawas, PhD, FHEA,

Maysoon M. Al-Amoud, MBBS, MSc, Saada M. Al-Orf, PhD, May N. Al-Muammar, PhD, Philip C. Calder, PhD.

\begin{abstract}
الأهداف : تقييم الحالة المعرفية لكبار السن في المملكة العربية السعودية.

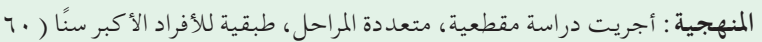

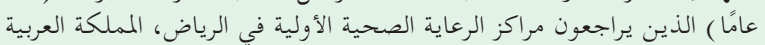

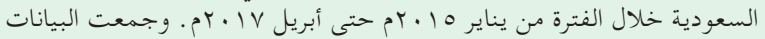

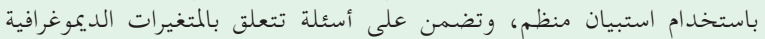

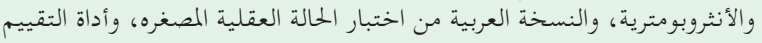
الغذائي المصغره، ومؤشر كاتز المعدل للاستقلال لأنشطة الحياة اليومية.

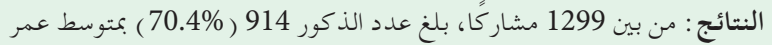

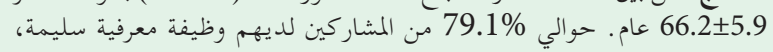

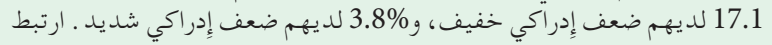

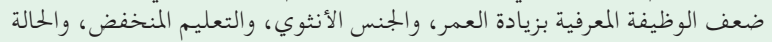

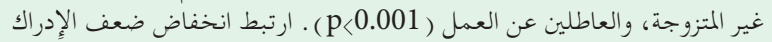

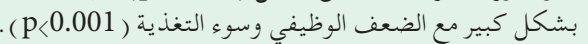

الخلاصة : ضعف الإدراك أثر على حوالي 21\% من المشاركين. ارتبط انخفاض

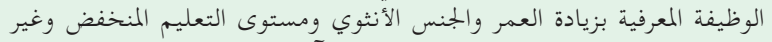

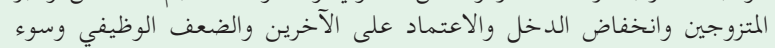

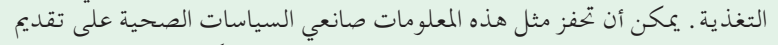

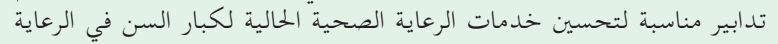
الأولية، بما في ذلك تقييم الوظيفة الإدراكية .
\end{abstract}

Objectives: To assess the cognitive status of older adults in Saudi Arabia.

Methods: This was a cross-sectional, multistage, stratified study of older individuals ( $\geq 60$ years of age) attending primary healthcare centres in Riyadh, Saudi Arabia between January 2015 and April 2017. We collected data using a structured questionnaire, which incorporated questions regarding demographic and anthropometric variables, the Arabic version of Mini-Mental State Examination, the Mini-Nutritional Assessment tool, and the Modified Katz Index of Independence in activities of daily living.

Results: Of the 1299 participants, 914 (70.4\%) were male, with a mean age of $66.2 \pm 5.9$ years. Approximately $79.1 \%$ of the participants had intact cognitive function,
17.1 had mild cognitive impairment, and 3.8\% had severe cognitive impairment. Impaired cognitive function was associated with increased age, female gender, low education, unmarried status, and unemployed $(p<0.001)$. Reduced cognitive impairment was significantly associated with functional impairment and malnutrition $(p<0.001)$.

Conclusion: Cognitive impairment affected around $21 \%$ of the participants. The reduced cognitive function was associated with increased age, female gender, low education level, unmarried, low income, dependency on others, functional impairment, and malnutrition. Such information could motivate health-policy makers to introduce appropriate measures to improve older adults' existing healthcare services in primary care, including cognitive function assessment.

Keywords: older adults, cognitive impairment, MiniMental State Examination Saudi Med J 2020; Vol. 41 (12): 1315-1323
doi: 10.15537/smj.2020.12.25576

From the Department of Family and Community Medicine (Alshammari), College of Medicine; from the Department of Community Health Sciences (Alhamdan), from the Department of Rehabilitation Sciences (Bindawas), from the Department of Community Health Sciences (Al-Orf, Al-Muammar), College of Applied Medical Sciences, King Saud University; from the Primary Health Care Centers (Al-Amoud), Ministry of Health, Riyadh, Kingdom of Saudi Arabia; from the Human Development and Health Academic Unit (Calder), Faculty of Medicine, University of Southampton, Southampton, United Kingdom; and from NIHR Southampton Biomedical Research Centre (Calder), University Hospital Southampton NHS Foundation Trust, Southampton, United Kingdom.

Received 21st July, 2020. Accepted 18th November 2020.

Address correspondence and reprint request to: Dr. Sulaiman A. Alshammari, Department of Family and Community Medicine, College of Medicine, King Saud University, Riyadh, Kingdom of Saudi Arabia. E-mail: amsahsa@gmail.com ORCID ID: https://orcid.org/0000-0001-9596-5590 
P opulation aging is emerging as a significant demographic trend worldwide. In 1990, persons aged 60 years or older constituted about $9.2 \%$ of the total global population. This rose to $11.7 \%$ in 2013 , and is projected to reach as high as $21.1 \%$ ( $>2$ billion) by 2050 . In several developing countries, the population of individuals aged 60 years or older is increasing at a faster rate than the population as a whole. ${ }^{1}$ In Saudi Arabia, older adults (60 years of age or older) made up about $5.6 \%$ of the total population in 2017, and this percentage is expected to reach $25 \%$ by 2050 . Life expectancy in the country is also expected to move from 74 to 82 years. ${ }^{2,3}$ With this rise in longevity, health workers should expect an increase in the risk of developing cognitive impairment. ${ }^{4}$ Moreover, evidence indicates the prevalence of dementia will triple worldwide over the next 2 decades. ${ }^{5}$

Significant causes of morbidity in old age include physical and mental illness due to loss of adaptability, the cumulative degenerative process, and the effects of iatrogenic disability and the social environment. ${ }^{6}$ The changes due to aging must fulfill 4 criteria: universal, progressive, intrinsic, and deleterious to the individual concerned. ${ }^{7}$ Moreover, lay care providers of elderly individuals often suffer from significant emotional, physical, and social morbidity. ${ }^{8,9}$

Even though elderly individuals are at higher risk of cognitive impairment than the rest of the population, health professionals should not consider these impairments as inevitable changes due to aging. Care providers should take prompt and aggressive action, especially in cases involving illness or injury. ${ }^{10-12}$

The assessment of an older adult's cognitive status is instrumental in identifying early changes in physiological status, determining the ability to learn, and evaluating responses to treatment. ${ }^{13,14}$ Studies evaluating the prevalence of cognitive impairment among community-dwelling older individuals in Saudi Arabia are scarce. This study aim to assess the cognitive status of older adults attending primary healthcare centers in Riyadh, Saudi Arabia.

Methods. This cross-sectional, multistage, stratified study was part of a research project evaluating the

Disclosure. This study was funded by the National Plan for Science, Technology, and Innovation, King Abdulaziz City for Science and Technology, Riyadh, Kingdom of Saudi Arabia (Grant No. 10-MED121902). internal environment of primary healthcare centers and assessing the health status of older people attending these centers in Riyadh, Saudi Arabia between January 2015 and April 2017.

This study included data from older adults visiting 15 primary healthcare centers (PHCCs) selected using the simple random sampling method from Riyadh, Saudi Arabia's 5 geographical areas. the investigators estimated the sample size as follows: The mean number of elderly attending a PHCC/month (679)*15 PHCCs=10185 elderly. Approximately $15 \%$ of these elderly was selected randomly $10185^{*} 15 \%=1528$

The authors chose 3 PHCCs from each of the following 5 areas: north, south, central, east, and west to represent the geographic sectors of the city of Riyadh. We included men and women aged $\geq 60$ years attending the selected PHCCs for routine primary care services. Within each sector, the older adults' sample size was determined proportional to the population attending the three selected PHCCs, and stratifying them according to gender. The older adults from each PHCC were selected consecutively. The detailed methodology has been described elsewhere. ${ }^{15,16}$

All of the participants or their caregivers provided written informed consent before the study. We assigned a number to each of the enrolled individuals that included the unique reference number of his or her primary healthcare. We maintained confidentiality throughout the investigation. The Ministry of Health ethics committee approved the study, which was supported by the National Plan for Science, Technology, and Innovation, King Abdulaziz City for Science and Technology, Saudi Arabia.

Two trained healthcare workers (one male and one female) from each primary healthcare were selected to conduct data collection under the regular supervision of one of the investigators. We assigned each of the selected healthcare workers a number (also including the centre reference number).

We collected socio-demographic data including age, marital status, educational status, and occupational status along with health data using a structured questionnaire. Cognitive status was assessed using the Mini-Mental State Examination (MMSE). ${ }^{17}$ It has been a proven effective and valid tool with high specificity and sensitivity to assess the mental status of older adults. ${ }^{18}$ The MMSE is specifically useful to assess the mental status of older adults in outpatient clinics, nursing homes, hospitals, and communities. ${ }^{19,20}$ It consists of 11 questions to measure 5 domains of cognitive function: orientation, registration, attention and calculation, recall, and language. The maximum score is $30 .{ }^{17}$ The 
MMSE score is used to classified elderly individuals' cognitive impairment into the following categories: 24-30, intact cognitive function; $18-23$, mild cognitive impairment; and $0-17$, severe cognitive impairment. Only 5-10 minutes are required to complete the MMSE. However, the instrument relies heavily on verbal responses, reading, and writing. Therefore, patients who are illiterate, hearing impaired, or visually impaired and those with other communication disorders were excluded from the study. As the MMSE was found valid for use within Arabic-speaking populations, ${ }^{21}$ we used the Arabic version of the MMSE in this study.

We also assessed the nutritional status of the participants using the Arabic version of the Mini-Nutritional Assessment $\left(\mathrm{MNA}^{\oplus}\right)$ tool, available from the Nestle Nutrition Institute. ${ }^{22}$ This tool has also been shown to be effective and valid with high specificity and sensitivity to determine the nutritional status of older adults. ${ }^{22-24}$ The $\mathrm{MNA}^{\oplus}$ scores range from $0-30$ points. Depending on the score, the individual is classified as well-nourished (24-30 points, at risk of malnutrition (17-23.5 points), or undernourished $(<17$ points). ${ }^{25}$

We also used the modified Katz Index of Independence in activities of daily living (ADL) such as eating, bathing, dressing, and toileting. ${ }^{26}$ The response was recorded according to the degree of difficulty (none, a little, a lot, and unable to). We identified participants as fully functional (score: 6), with moderate functional impairment (score: 3-5), or with severe functional impairment (score: 0-2). All the instruments (MMSE, MNA, and ADL) are reliable and valid. ${ }^{21,27,28}$

Body mass index (BMI) was determined by dividing the weight in $\mathrm{kg}$ by the square of height in meters. We classified them as underweight $\left(<18.5 \mathrm{~kg} / \mathrm{m}^{2}\right)$, normal weight $\left(18.5-24.9 \mathrm{~kg} / \mathrm{m}^{2}\right)$, overweight $\left(25.0-29.9 \mathrm{~kg} / \mathrm{m}^{2}\right)$, or obese $\left(\geq 30 \mathrm{~kg} / \mathrm{m}^{2}\right)$ according to the World Health Organization (WHO) international standard of BMI. ${ }^{25}$

A pilot study of 20 elderly individuals in 4 primary healthcare centers in Riyadh, Saudi Arabia was conducted to ascertain that the questions were understood, to estimate the time required to complete the questionnaire, and to explore any obstacles or constraints. Field supervisors revised the questionnaire accordingly and tested its clarity and feasibility.

Statistical analysis. Data were analyzed using Statistical Package for Social Sciences, version 22 (IBM Corp, Armonk, NY, USA) for statistical analysis. We presented age as a continuous variable (the mean \pm standard deviation) in the text, while we presented all other variables as categorical variables (the frequency and percentage) in the tables.
Bivariate relationships or differences of each categorical variable with cognitive impairment were examined by the Chi-square test $\left(\chi^{2}\right)$, while multivariate relationships between the cognitive impairment and various variables were determined by logistic regression. The binary logistic regression was applied, in which cognitive status was taking as the dependent variable and other variables as independent variables. The probability of cognitive impairment risk over the probability of no risk of cognitive impairment was presented in the form of an odds ratio. Differences were considered significant at $p<0.05$, at $95 \%$ confidence interval (CI).

Results. The study included 1299 older adults who completed the MMSE. The response rate was $85 \%$. Table 1 shows the social-demographic characteristics of the participants according to cognitive status, measured using the MMSE. Of the participants, $70.4 \%$ were males. The mean age was $66.2 \pm 5.9$ years, with ages ranging from 60 to 93 years. The mean ages for male was $67.0 \pm 6.8$ years and $68.1 \pm 6.5$ years for female. Most participants (77.3\%) were aged 60-69 years, married (89.3\%), and unemployed (78.4\%). The study population included $18.0 \%$ from the city's Central, $33.4 \%$ from the Western, $16.0 \%$ from the Eastern sector, $20.4 \%$ from the Southern, and $12.1 \%$ from the Northern.

Approximately $79.1 \%$ of the participants had intact cognitive function, whereas $17.1 \%$ had mild cognitive impairment and 3.8\% had severe cognitive impairment. Impaired cognitive function was associated with increased age, female gender, low education level, being unmarried, unemployed, low income, and the East and West sectors $(p<0.001)$.

Table 2 presents the living arrangements, dependency on others, ADL, nutritional status, and BMI of the participants according to MMSE score. Only 5.6\% of the participants lived alone. The majority (96.2\%) were classified as fully functional based on their ADL scores, and $86.5 \%$ had a normal nutritional status. Nevertheless, $41.2 \%$ were overweight, and $39.4 \%$ were obese. Reduced cognitive impairment was significantly associated with dependency on others, functional impairment, and malnutrition $(p<0.001)$.

Table 3 demonstrates that the binary logistic regression for the risk of cognitive impairment MMSE versus Age, level of education, marital status, working status, income, area of residence, help requirement, $\mathrm{ADL}$, and MNA maintained a marked association after adjusting for other variables. Other variables such as the participants gender, housing ownership, living 
Table 1 - Socio-demographic characteristics by Mini-Mental State Examination score ( $\mathrm{N}=1299)$.

\begin{tabular}{|c|c|c|c|c|c|}
\hline \multirow[t]{2}{*}{ Characteristics } & \multirow[b]{2}{*}{$\begin{array}{l}\text { Total } \\
\mathrm{N}(\%)\end{array}$} & \multicolumn{3}{|c|}{ Examination scores } & \multirow[t]{2}{*}{$P$-value } \\
\hline & & $\begin{array}{c}0-17 \\
50(3.8)\end{array}$ & $\begin{array}{c}18-23 \\
222(17.1)\end{array}$ & $\begin{array}{c}24-30 \\
1027(79.1)\end{array}$ & \\
\hline \multicolumn{6}{|l|}{ Age (years) } \\
\hline $60-69$ & $1004(77.3)$ & $21(2.1)$ & $132(13.1)$ & $851(84.8)$ & \multirow{3}{*}{0.001} \\
\hline $70-79$ & $256(19.7)$ & $20(7.8)$ & $73(28.5)$ & $163(63.7)$ & \\
\hline $80+$ & $39 \quad(3.0)$ & $9(23.1)$ & $17(43.6)$ & $13(33.3)$ & \\
\hline \multicolumn{6}{|l|}{ Gender } \\
\hline Male & $914(70.4)$ & $26(2.8)$ & $153(16.7)$ & $735(80.4)$ & \multirow{2}{*}{0.011} \\
\hline Female & $385(29.6)$ & $24(6.2)$ & $69(17.9)$ & $292(75.8)$ & \\
\hline \multicolumn{6}{|l|}{ Education level } \\
\hline Read and write & $612(47.1)$ & $31(5.1)$ & $119(19.4)$ & $462(75.5)$ & \multirow{3}{*}{0.006} \\
\hline $\begin{array}{l}\text { Primary and } \\
\text { intermediate }\end{array}$ & $492(37.9)$ & $14(2.8)$ & $83(16.9)$ & $395(80.3)$ & \\
\hline $\begin{array}{l}\text { Secondary and } \\
\text { university }\end{array}$ & $195(15.0)$ & $5(2.6)$ & $20(10.3)$ & $170(87.2)$ & \\
\hline \multicolumn{6}{|l|}{ Marital status } \\
\hline Married & $1160(89.3)$ & $36(3.1)$ & $181(15.6)$ & $943(81.3)$ & \multirow{2}{*}{0.001} \\
\hline Unmarried & $139(10.7)$ & $14(10.1)$ & $41(29.5)$ & $84(60.4)$ & \\
\hline \multicolumn{6}{|l|}{ Occupation } \\
\hline Employed & $281(21.6)$ & $3(1.1)$ & $29(10.3)$ & $249(88.6)$ & \multirow{2}{*}{0.001} \\
\hline Unemployed & $1018(78.4)$ & $47(4.6)$ & $193(19.0)$ & $778(76.4)$ & \\
\hline \multicolumn{6}{|c|}{ Income (Saudi Riyals) } \\
\hline less than 6000 & $253(19.5)$ & $21(8.3)$ & $38(15.0)$ & $194(76.7)$ & \multirow{3}{*}{0.001} \\
\hline $6000+$ & $353(27.2)$ & $9(2.5)$ & $49(13.9)$ & $295(83.6)$ & \\
\hline No answer & $693(53.3)$ & $20(2.9)$ & $135(19.5)$ & $538(77.6)$ & \\
\hline \multicolumn{6}{|l|}{ Housing } \\
\hline Rent & $218(16.8)$ & $6(2.8)$ & $25(11.5)$ & $187(85.8)$ & \multirow{3}{*}{0.031} \\
\hline Owned & $1019(78.4)$ & $43(4.2)$ & $181(17.8)$ & $795(78.0)$ & \\
\hline Other & $62(4.8)$ & 1 (1.6) & $16(25.8)$ & 45 (72.6) & \\
\hline \multicolumn{6}{|l|}{ Residence } \\
\hline North & $157(12.1)$ & $4(2.5)$ & $14 \quad(8.9)$ & $139(88.5)$ & \multirow{5}{*}{0.001} \\
\hline Central & $234(18.0)$ & $5(2.1)$ & $27(11.5)$ & $202(86.3)$ & \\
\hline South & $268(20.6)$ & $7(2.6)$ & $63(23.5)$ & $198(73.9)$ & \\
\hline East & $207(15.9)$ & $14(6.8)$ & $63(30.4)$ & $130(62.8)$ & \\
\hline West & $433(33.3)$ & $20(4.6)$ & $55(12.7)$ & $358(82.7)$ & \\
\hline
\end{tabular}

arrangement, BMI failed to predict the risk of cognitive impairment.

While non-modifiable risk factors such as increased in age $(\mathrm{OR}=6.646 ; 95 \% \mathrm{CI}=3.007-14.688)$, modifiable risk factors such as low level of education $(\mathrm{OR}=2.5435$; 95\% $\mathrm{CI}=1.496-4.322)$, lower performance in $\mathrm{ADL}$ 4.092(1.415-11.839) $\quad(\mathrm{OR}=4.092 ; \quad 95 \% \quad \mathrm{CI}=1.415-$ $11.839)$ and malnutritional status MNA $(\mathrm{OR}=2.598$; $95 \% \mathrm{CI}=0.490-13.785)$ were associated with increased risk of cognitive decline.
Discussion. As the world's population ages, the decline of cognitive function among older adults are becoming common and poses significant threats to their mental and physical wellbeing; moreover, its burden extends to family caregivers. ${ }^{29}$ Cognitive impairment affects the quality of life and increases health care costs..$^{30}$ In the present study, $17.1 \%$ of the participants were affected by mild cognitive impairment and 3.8\% were affected by severe cognitive impairment. These are less than the $45 \%$ (mild $38.6 \%$ ) reported in a cross- 
Table 2 - Living arrangement, activities of daily living, and nutritional assessment by Mini-Mental State Examination score $(\mathrm{N}=1299)$.

\begin{tabular}{|c|c|c|c|c|c|}
\hline \multirow[t]{2}{*}{ Characteristics } & \multirow[b]{2}{*}{$\begin{array}{c}\text { Total } \\
\text { N (\%) }\end{array}$} & \multicolumn{3}{|c|}{ Examination scores } & \multirow[t]{2}{*}{$P$-value } \\
\hline & & $\begin{array}{c}0-17 \\
50(3.8)\end{array}$ & $\begin{array}{c}18-23 \\
222(17.1)\end{array}$ & $\begin{array}{c}24-30 \\
1027(79.1)\end{array}$ & \\
\hline \multicolumn{6}{|l|}{ Living arrangement } \\
\hline Alone & 73 (5.6) & $2(2.7)$ & $9(12.3)$ & $62(84.9)$ & \multirow{2}{*}{0.447} \\
\hline With relative & $1226(94.4)$ & $48(3.9)$ & $213(17.4)$ & $965(78.7)$ & \\
\hline \multicolumn{6}{|l|}{ Needs help } \\
\hline No & $1075(82.8)$ & $33(3.1)$ & $160(14.9)$ & $882(82.0)$ & \multirow{2}{*}{0.001} \\
\hline Yes & $224(17.2)$ & $17(7.6)$ & $62(27.7)$ & $145(64.7)$ & \\
\hline \multicolumn{6}{|l|}{ Activities of daily living } \\
\hline Severe functional impairment & $23(1.8)$ & $11(47.8)$ & $3(13.0)$ & $9(39.1)$ & \multirow{3}{*}{0.001} \\
\hline Moderate functional impairment & $26(2.0)$ & $6(23.1)$ & $10(38.5)$ & $10(38.5)$ & \\
\hline Fully functional & $1250(96.2)$ & $33 \quad(2.6)$ & $209(16.7)$ & $1008(80.6)$ & \\
\hline \multicolumn{6}{|l|}{ Nutrition status } \\
\hline Normal & $1124(86.5)$ & $33 \quad(2.9)$ & $169(15.0)$ & $922(82.0)$ & \multirow{3}{*}{0.001} \\
\hline Risk of malnutrition & $167(12.9)$ & $14 \quad(8.4)$ & $52(31.1)$ & $101(60.5)$ & \\
\hline Malnourished & $8(0.6)$ & $3(37.5)$ & $1(12.5)$ & $4(50.0)$ & \\
\hline \multicolumn{6}{|l|}{ Body mass index } \\
\hline$<25$ & $252(19.4)$ & $14 \quad(5.6)$ & $44(17.5)$ & $194(77.0)$ & \multirow{3}{*}{0.31} \\
\hline $25-29.9$ & $535(41.2)$ & $16 \quad(3.0)$ & $99(18.5)$ & $420(78.5)$ & \\
\hline $30+$ & $512(39.4)$ & $20 \quad(3.9)$ & $79(15.4)$ & $413(80.7)$ & \\
\hline
\end{tabular}

Scores: 24-30 intact cognitive function, 18-23 mild cognitive impairment, 0-17 severe cognitive impairment

sectional study of older adults in the family medicine clinics affiliated with King Faisal Specialist Hospital and Research Centre, Riyadh, Saudi Arabia using the Montreal Cognitive Assessment test. ${ }^{31}$ Yet, our findings are consistent with the 5-7\% global prevalence of dementia and the $10-20 \%$ prevalence of cognitive impairment among the elderly. ${ }^{32,33}$ The regional prevalences of dementia and mild cognitive impairment both range between $4.4 \%$ and $32 \% .^{34-36}$ But better than $69.8 \%$ of Morocco's older adults were classed as having cognitive impairment. The malnutrition, gender and low education were risk factors for cognitive impairment, when moderate level of physical activity was a protective factor compared to the limited level. ${ }^{37}$

The rising rate of cognitive impairment in Saudi Arabia may be attributed to the widespread occurrence of risk factors for dementia. ${ }^{38,39}$ These risk factors include smoking $(21.4 \%)$, diabetes mellitus (25.0\%), hypertension (36.0\%), and hypercholesterolemia (40.0\%). ${ }^{41-43}$ Other possible risk factors for cognitive impairment include malnutrition and low education..$^{30,37}$

Mild cognitive impairment is a transitional stage before dementia, and the annual conversion rate to dementia reaches up to $20.0 \% .{ }^{44,45}$ Early detection of cognitive impairment can slow progression of the disease and offers medical, emotional, and financial benefits to affected individuals and their families. ${ }^{46,29}$ There is a need to control risk factors for cognitive impairment in Saudi Arabia because, as the aging population grows, the prevalence of dementia could increase significantly.

Our study revealed a significant association between impaired cognitive function and increased age, female gender, low education level, and low income. This finding is consistent with previous studies in which increased age, female gender, low educational level, and low income were also associated with poor cognitive performance. ${ }^{37,47,48}$ However, our findings differed from those of the Chinese longitudinal healthy longevity survey $(\mathrm{N}=13,586)$, which did not reveal gender differences in cognitive function across two age cohorts. ${ }^{49}$ In later life, reading was protective of cognitive function. A decreased risk of cognitive impairment for older adults at all levels of education has been correlated with regular reading practises We should encourage older adults to read as much as they can from their favorable literature such as the holy Quran, social media, and newspaper.

An unmarried status was associated with reduced cognitive function. This finding is similar to that of a 
Table 3 - Binary logistic regression: influence of the socio-demographic characteristics, activities of daily living, and nutrition status on the risk of severe or mild cognitive impairment $(\mathrm{N}=1299)$.

\begin{tabular}{|c|c|c|c|c|c|}
\hline \multirow[b]{2}{*}{ Characteristics } & \multirow[b]{2}{*}{ Total N (\%) } & \multicolumn{2}{|c|}{ Mini-Mental State Examination } & \multirow[b]{2}{*}{$\begin{array}{l}\text { Unadjusted OR } \\
\quad(95 \% \mathrm{CI})\end{array}$} & \multirow[b]{2}{*}{$\begin{array}{l}\text { Adjusted OR } \\
(95 \% \mathrm{CI})\end{array}$} \\
\hline & & $\begin{array}{c}\text { Impaired } \\
<24 \\
272(20.9) \\
\end{array}$ & $\begin{array}{c}\text { Not impaired } \\
24-30 \\
1027(79.1) \\
\end{array}$ & & \\
\hline \multicolumn{6}{|l|}{ Age (years) } \\
\hline $60-69$ & $1004(77.3)$ & $153(15.2)$ & $851(84.8)$ & & Reference \\
\hline $70-79$ & $256(19.7)$ & $93(36.3)$ & $163(63.7)$ & $3.173(2.334-4.316)$ & $2.845(2.013-4.020)$ \\
\hline $80+$ & $39 \quad(3.0)$ & $26(66.7)$ & $13(33.3)$ & $11.124(5.593-22.126)$ & $6.646(3.007-14.688)$ \\
\hline \multicolumn{6}{|l|}{ Educational level } \\
\hline Secondary and university & $195(15.0)$ & $25(12.8)$ & $170(87.2)$ & & Reference \\
\hline Read and write & $612(47.1)$ & $150(24.5)$ & $462(75.5)$ & $2.208(1.396-3.492)$ & $2.543(1.496-4.322)$ \\
\hline Primary and intermediate & $492(37.9)$ & $97(19.7)$ & $395(80.3)$ & $1.670(1.039-2.685)$ & $1.937(1.124-3.339)$ \\
\hline \multicolumn{6}{|l|}{ Marital status } \\
\hline Married & $1160(89.3)$ & $217(18.7)$ & $943(81.3)$ & & Reference \\
\hline Unmarried & $139(10.7)$ & $55(39.6)$ & $84(60.4)$ & $2.845(1.964-4.122)$ & $2.500(1.591-3.930$ \\
\hline \multicolumn{6}{|l|}{ Occupation } \\
\hline Employed & 281 (21.6) & $32(11.4)$ & $249(88.6)$ & & Reference \\
\hline Unemployed & $1018(78.4)$ & $240(23.6)$ & $778(76.4)$ & $2.400(1.616-3.565)$ & $1.531(0.985-2.381)$ \\
\hline \multicolumn{6}{|l|}{ Income (Saudi Riyals) } \\
\hline $6000+$ & $353(27.2)$ & $58(16.4)$ & $295(83.6)$ & & Reference \\
\hline less than 6000 & $253(19.5)$ & $59(23.3)$ & $194(76.7)$ & $1.056(0.750-1.486)$ & $1.825(1.167-2.855)$ \\
\hline No answer & $693(53.3)$ & $155(22.4)$ & $538(77.6)$ & $0.682(0.489-0.952)$ & $0.632(0.406-0.982)$ \\
\hline \multicolumn{6}{|l|}{ Residence } \\
\hline North area 1 & $157(12.1)$ & $18(11.5)$ & $139(88.5)$ & & Reference \\
\hline Central area 2 & $234(18.0)$ & $32(13.7)$ & $202(86.3)$ & $0.618(0.356-1.072)$ & $0.372(0.188-0.736)$ \\
\hline South area 3 & $268(20.6)$ & $70(26.1)$ & $198(73.9)$ & $1.688(1.167-2.441)$ & $1.348(0.876-2.077)$ \\
\hline East area 4 & $207(15.9)$ & $77(37.2)$ & $130(62.8)$ & $2.827(1.941-4.118)$ & $4.063(2.545-6.486)$ \\
\hline West area 5 & $433(33.3)$ & $75(17.3)$ & $358(82.7)$ & $0.756(0.483-1.184)$ & $0.439(0.256-0.752)$ \\
\hline \multicolumn{6}{|l|}{ Needs help } \\
\hline No & $1075(82.8)$ & $193(18.0)$ & $882(82.0)$ & & Reference \\
\hline Yes & $224(17.2)$ & $79(35.3)$ & $145(64.7)$ & $2.490(1.817-3.413)$ & $3.265(2.157-4.941)$ \\
\hline \multicolumn{6}{|l|}{ Activities of daily living } \\
\hline Fully functional & $1250(96.2)$ & $242(19.4)$ & 1008 (80.6) & & Reference \\
\hline Moderate impairment & $26(2.0)$ & $16(61.5)$ & $10(38.5)$ & $6.479(2.772-15.145)$ & $2.499(1.022-6.113)$ \\
\hline Severe impairment & $23 \quad(1.8)$ & $14(60.9)$ & $9(39.1)$ & $6.664(2.987-14.868)$ & $4.092(1.415-11.839)$ \\
\hline \multicolumn{6}{|l|}{ Nutrition status } \\
\hline Normal & $1124(86.5)$ & $202(18.0)$ & $922(82.0)$ & & Reference \\
\hline Risk of malnutrition & $167(12.9)$ & $66(39.5)$ & $101(60.5)$ & $2.983(2.111-4.214)$ & $1.875(1.228-2.863$ \\
\hline Malnourished & $8 \quad(0.6)$ & $4(50.0)$ & $4(50.0)$ & $4.564(1.132-18.403)$ & $2.598(0.490-13.785)$ \\
\hline
\end{tabular}

previous study, which reported that being married may serve as a buffer against the negative cognitive impacts of aging. ${ }^{51}$ A sizeable number of our older adults are still living with spouse particularly men. This may contribute to their low cognitive impairment. Only $5.6 \%$ of the participants in our study lived alone. The cognitive function of those living alone and those living with relatives did not differ significantly. This finding confirmed that of a previous study in which those who lived alone did not show declines in cognitive score over 2 years, even though they reported greater feelings of emotional loneliness than those living with others. ${ }^{52}$ 
Interestingly, past literature supports our finding that working is protective. So policy makers may find this data in support of increasing the age of retirement. Also create an opportunities for older adults to participate in paid or voluntary work. Such effort may prevent loneliness and generate some income to them. This finding is consistent with that of a study carried out by Xue et al..$^{53}$ They found the cognitive function of individuals who were not currently working to be inferior to that of their counterparts. They suggest the cognitively stimulating activities associated with employment may benefit the memory of older adults. ${ }^{53}$

The majority $(96.2 \%)$ of participants in our study were able to perform ADL independently, and we found a significant association between poor cognitive function and functional impairment. This is consistent with the results of a previous study that suggest screening for independence in ADL could serve as an additional and potentially economically viable indicator to assess the risk of poor cognitive function. ${ }^{54,55}$ Health decision makers and professional should work on improving older adults ADL, since this modifiable factors may help to improve the overall cognitive function of the older adults. Also, exercisebased therapeutic strategies aiming to improve physical fitness should be implemented as recommended by previous investigators. ${ }^{37,56}$ Provided the protective effects of physical activity and physical function on the cognitive decline at later age, decision-makers should plan health promotion programs of regular physical activity, provide physical fitness facilities to improve physical and cognitive function among people across all ages. Also improve the provision of physiotherapy. These maneuver are also supported by the previous literature. ${ }^{37,57}$

Approximately $41 \%$ of the participants were overweight, and $39.4 \%$ were obese according to the WHO classification. A lower BMI was associated with a decline in cognitive function, which is similar to the findings of a previous study in the United States. The investigators found a lower BMI was associated with faster rates of cognitive decline, specifically, semantic and episodic memory. ${ }^{58}$ Although malnutrition risk is well investigated in older adult care facilities, few researches have been published to address communitydwelling older adults' concerns.

We found a significant association between nutritional status and cognitive function. A previous study found that those with cognitive impairment were at higher risk of malnutrition, which can have significant adverse effects on quality of life, clinical outcomes, and morbidity and mortality. ${ }^{59}$ Malnutrition is one of the health problems in the elderly population, which increases the risk of poor clinical outcomes. ${ }^{60}$ These indicate that nutritional status monitoring can prevent it from leading to cognitive impairment. Thus, health professionals should assess the nutritional and cognitive status of the older adults regularly to the early dictation and timely management.

Screening, treatment, and rehabilitation should be integrated to prevent unnecessary suffering and prolonged dependency among the elderly. A previous study reported that, while a majority of older adults and primary care physicians have a positive attitude regarding regular cognitive assessments, only $16.0 \%$ of seniors receive one. ${ }^{29} \mathrm{~A}$ family physician and his or her team have a pivotal role in the assessment of an older adult's cognitive status and in monitoring responses to treatment. The WHO recommends age-friendly primary healthcare to achieve the goal of successful aging. ${ }^{61}$ So far, in Saudi Arabia, primary health care centers provide free of charge preventive and curative services to Saudi Citizens.

Recently, aging has become a priority for primary healthcare $s$ in Saudi Arabia, particularly in respect to continuous training programs targeting health workers in these centers provided by the Ministry of Health in the area of geriatric care. We recommend the areas of training, such as health screening, assessment, treatment, and rehabilitation, be based on evidence-based studies, practices, and resources. With this foundation, progress toward further investment in health priorities for older adults can be better assured, thereby improving these individuals' quality of life.

Study limitations. The cross-sectional design of this study prevented us from establishing causality. Though the study was conducted in the biggest city in Saudi Arabia, our findings may not be generalizable to all areas of the country.

In conclusion, approximately $21 \%$ of the participants had cognitive impairment associated with increased age, female gender, low education level, unmarried, and a low income. Also, reduced cognitive function was associated with dependency on others, functional impairment, and malnutrition. The current study will help health-policy makers take appropriate measures to improve the existing healthcare services provided to older adults. Comprehensive geriatric assessment including cognitive function of older adults in primary healthcare would inevitably reduce these individuals' risk of developing complications and improve their quality of life. 
Acknowledgment. The study was funded by the National Plan for Science, Technology, and Innovation (MAARIFAH), King Abdulaziz City for Science and Technology, Kingdom of Saudi Arabia (Grant No. 10-MED121902). We would like to thank all of the healthcare providers involved in the research and the Ministry of Health for permitting us to conduct the study. Lastly we would like to thank Editage (www.editage.com) for the English language editing.

\section{References}

1. Sander M, Oxlund B, Jespersen A, Krasnik A, Mortensen EL, Westendorp RGJ, et al. The challenges of human population ageing. Age Ageing 2015; 44: 185-187.

2. United Nations. World Population Ageing 2013. [Updated 2013. 2020 Accessed October 4]. Available from URL: https:// www.un.org/en/development/desa/population/publications/ pdf/ageing/WorldPopulationAgeing2013.pdf

3. Abusaaq HI. SAMA Working Paper: Population Aging In Saudi Arabia. Saudi Arabian Monetary Agency. [Updated 2015 February. 2020 Accessed October 7]. Available from URL: https://docplayer.net/18400957-Sama-working-paperpopulation-aging-in-saudi-arabia-february-2015-hussain-iabusaaq-economic-research-department-saudi-arabian-monetary-agency.html

4. Batum K, Çinar N, Şahin Ş, Çakmak MA, Karşidağ S. The connection between MCI and Alzheimer disease: neurocognitive clues. Turk J Med Sci 2015; 45: 1137-1140.

5. Norton S, Matthews FE, Barnes DE, Yaffe K, Brayne C. Potential for primary prevention of Alzheimer's disease: an analysis of population-based data. Lancet Neurol 2014; 13: 788-794.

6. Khoja AT, Aljawadi MH, Al-Shammari SA, Mohamed AG, Al-Manaa HA, Morlock L, et al. The health of Saudi older adults; results from the Saudi National Survey for Elderly Health (SNSEH) 2006-2015. Saudi Pharm J 2018; 26: 292-300.

7. Rudnicka E, Napierała P, Podfigurna A, Męczekalski B, Smolarczyk R, Grymowicz M. The World Health Organization (WHO) approach to healthy ageing. Maturitas 2020; 139: 6-11.

8. Alshammari SA, Alzahrani AA, Alabduljabbar KA, Aldaghri AA, Alhusainy YA, Khan MA, et al. The burden perceived by informal caregivers of the elderly in Saudi Arabia. J Family Community Med 2017; 24: 145.

9. Or R, Kartal A. Influence of caregiver burden on well-being of family member caregivers of older adults. Psychogeriatrics 2019; 19: 482-490.

10. Kelly ME. The potential of a relational training intervention to improve older adults' cognition. Behav Anal Pract 2020; 13: 684-697.

11. Livingston G, Huntley J, Sommerlad A, Ames D, Ballard C, Banerjee $S$, et al. Dementia prevention, intervention, and care: 2020 report of the Lancet Commission. Lancet 2020; 396: 413-446.

12. Subramaniam H. Co-morbidities in dementia: time to focus more on assessing and managing co-morbidities. Age Ageing 2019; 48: 314-315.

13. Garrard JW, Cox NJ, Dodds RM, Roberts HC, Sayer AA. Comprehensive geriatric assessment in primary care: a systematic review. Aging Clin Exp Res 2020; 32: 197-205.
14. Patnode CD, Perdue LA, Rossom RC, Rushkin MC, Redmond $\mathrm{N}$, Thomas RG, et al. Screening for cognitive impairment in older adults: updated evidence report and systematic review for the US Preventive Services Task Force. Jama 2020; 323: 764-85

15. Alhamadan AA, Bindawas SM, Alshammari SA, Al-Amoud MM, Al-Orf SM, Al-Muammar MN, et al. Prevalence of malnutrition and its association with activities of daily living in older adults attending primary health care centers: A multistage cross-sectional study. Progin Nutr 2019: 21: 1011-1018.

16. Alhamdan AA, Alshammari SA, Al-Amoud MM, Hameed TA, Al-Muammar MN, Bindawas SM, et al. Evaluation of health care services provided for older adults in primary health care centers and its internal environment. A step towards agefriendly health centers. Saudi Med J 2015; 36:1091-1096.

17. Folstein MF, Folstein SE, McHugh PR. "Mini-mental state": a practical method for grading the cognitive state of patients for the clinician. J Psychiatr Res 1975;12:189-198.

18. Vellas B, Guigoz Y, Garry PJ, Nourhashemi F, Bennahum D, Lauque S, et al. The Mini Nutritional Assessment (MNA) and its use in grading the nutritional state of elderly patients. Nutrition 1999; 15: 116-122.

19. Schneider SM, Hebuterne X. Use of nutritional scores to predict clinical outcomes in chronic diseases. Nutr Rev 2000; 58 (2 Pt 1): 31-38.

20. Guigoz Y. The Mini Nutritional Assessment (MNA) review of the literature--What does it tell us? J Nutr Health Aging 2006; 10: 466-485; discussion 485-487.

21. El-Hayeck R, Baddoura R, Wehbé A, Bassil N, Koussa S, Abou Khaled K, et al. An Arabic version of the mini-mental state examination for the Lebanese population: Reliability, validity, and normative data. J Alzheimers Dis 2019; 71: 525-540

22. Guigoz Y. The Mini Nutritional Assessment $\left(\mathrm{MNA}^{\oplus}\right)$ Review of the literature-What does it tell us? J Nutr Health Aging 2006; 10: 466-485.

23. Vellas B, Guigoz Y, Garry PJ, Nourhashemi F, Bennahum D, Lauque S, et al. The Mini Nutritional Assessment (MNA) and its use in grading the nutritional state of elderly patients. Nutrition 1999; 15: 116-122.

24. Schneider SM, Hebuterne X. Use of nutritional scores to predict clinical outcomes in chronic diseases. Nutr Rev 2000; 58: $31-38$

25. World Health Organization. Physical status: The use of and interpretation of anthropometry, Report of a WHO Expert Committee. [Updated 1995. 2020 Accessed October 9]. Available from URL: who.int/childgrowth/publications/ physical_status/en/

26. Katz S, Downs TD, Cash HR, Grotz RC. Progress in development of the index of ADL. Gerontologist 1970;10: 20-30.

27. Al-Atty A, Muhammad F, Abou Hashem RM, Abd Elaziz KM. Prevalence of malnutrition in recently hospitalized elderly in Cairo using a valid and reliable short form of Arabic version of Mini-Nutritional Assessment (MNA-SF-A). Middle East Age Ageing 2012; 83: 1-5.

28. Nasser R, Doumit J. Validity and reliability of the Arabic version of activities of daily living (ADL). BMC 2009; 9: 1.

29. Association As. 2019 Alzheimer's disease facts and figures. Alzheimers Dement 2019;15: 321-387.

30. Suma S, Furuta M, Yamashita Y, Matsushita K. Aging, Mastication, and Malnutrition and Their associations with cognitive disorder: evidence from epidemiological data. Curr Oral Health Rep 2019; 6: 89-99. 
31. Alkhunizan M, Alkhenizan A, Basudan L. Prevalence of mild cognitive impairment and dementia in Saudi Arabia: A community-based study. Dement Geriatr Cogn Dis Extra 2018; 8: 98-103.

32. Prince M, Bryce R, Albanese E, Wimo A, Ribeiro W, Ferri CP. The global prevalence of dementia: a systematic review and metaanalysis. Alzheimers Dement 2013; 9: 63-75.

33. Langa KM, Levine DA. The diagnosis and management of mild cognitive impairment: a clinical review. JAMA 2014; 312 : 2551-2561.

34. Sweed HS, El-awam AE. Cognitive impairment among residents of elderly homes in Cairo, Egypt. MECP 2010; 84: 1-6.

35. Afgin AE, Massarwa M, Schechtman E, Israeli-Korn SD, Strugatsky R, Abuful A, et al. High prevalence of mild cognitive impairment and Alzheimer's disease in arabic villages in northern Israel: impact of gender and education. J Alzheimers Dis 2012; 29: 431-439.

36. Zaitoun A, Al Mảmoun A, Sarhan M, Selim A, Mousa G. Epidemiological study of dementia after retirement. Egypt J Neurol Psychiatr Neurosurg 2008; 45: 65-74.

37. Talhaoui A, Aboussaleh Y, Ahami A, Sbaibi R, Agoutim N. Association between malnutrition and cognitive impairment among Morocco's older adults. Open J Med Psychol 2019; 8: $1-14$.

38. Rizzi L, Rosset I, Roriz-Cruz M. Global epidemiology of dementia: Alzheimer's and vascular types. Biomed Res Int 2014; 2014: 1-8.

39. Sachs-Ericsson N, Blazer DG. The new DSM-5 diagnosis of mild neurocognitive disorder and its relation to research in mild cognitive impairment. Aging Ment Health 2015; 19: 1-12.

40. Algabbani AM, Almubark R, Althumiri N, Alqahtani A, BinDhim N. The prevalence of cigarette smoking in Saudi Arabia in 2018. Food and Drug Regulatory Science Journal. 2018; 1: 1-13.

41. Robert AA, Al Dawish MA. The worrying trend of diabetes mellitus in Saudi Arabia: an urgent call to action. Curr Diabetes Rev 2019; 16: 204-210.

42. Yusufali AM, Khatib R, Islam S, Alhabib KF, Bahonar A, Swidan HM, et al. Prevalence, awareness, treatment and control of hypertension in four Middle East countries. J Hypertens 2017; 35: 1457-1464.

43. AlQuaiz AM, Kazi A, Youssef RM, Alshehri N, Alduraywish SA. Association between standardized vitamin $25(\mathrm{OH})$ D and dyslipidemia: a community-based study in Riyadh, Saudi Arabia. Environ Health Prev Med 2020; 25: 1-9.

44. Lin JS, O’Connor E, Rossom RC, Perdue LA, Eckstrom E. Screening for cognitive impairment in older adults: a systematic review for the US Preventive Services Task Force. Ann Intern Med 2013; 159: 601-612.

45. Etgen T, Sander D, Bickel H, Förstl H. Mild cognitive impairment and dementia: the importance of modifiable risk factors. Dtsch Arztebl Int 2011; 108: 743-750.

46. Mukadam N, Cooper C, Kherani N, Livingston G. A systematic review of interventions to detect dementia or cognitive impairment. International journal of geriatric psychiatry. 2015; 30: 32-45.

47. Huntley J, Corbett A, Wesnes K, Brooker H, Stenton R, Hampshire A, et al. Online assessment of risk factors for dementia and cognitive function in healthy adults. Int $J$ Geriatr Psychiatry 2018; 33: e286-e293.
48. Han R, Tang Z, Ma L. Related factors of cognitive impairment in community-dwelling older adults in Beijing Longitudinal Study of Aging. Aging Clin Exp Res 2019; 31: 95-100.

49. Miyawaki CE, Liu M. Gender differences in cognitive impairment among the old and the oldest-old in China. Geriatr Gerontol Int 2019;19: 586-592.

50. Chang Y-H, Wu I-C, Hsiung CA. Reading activity prevents long-term decline in cognitive function in older people: evidence from a 14-year longitudinal study. Int Psychogeriatr 202; 5: 1-12.

51. Cheng GH, Chan A, Lo JC. Importance of social relationships in the association between sleep duration and cognitive function: data from community-dwelling older Singaporeans. Int Psychogeriatr 2018; 30: 893-901.

52. Evans IEM, Llewellyn DJ, Matthews FE, Woods RT, Brayne C, Clare L, et al. Living alone and cognitive function in later life. Arch Gerontol Geriatr 2019; 81: 222-233.

53. Xue B, Cadar D, Fleischmann M, Stansfeld S, Carr E, Kivimaki $M$, et al. Effect of retirement on cognitive function: the Whitehall II cohort study. Eur J Epidemiol 2018; 33: 989-1001.

54. Zhang Y, Gu Y, Zhang Y, Liu X, Zhang Y, Wu W, et al. Effect of sociodemographic and physical activity on cognitive function in older adults: A nationwide cross-sectional survey. Int J Geriatr Psychiatry 2019; 34: 243-248.

55. Roehr S, Riedel-Heller SG, Kaduszkiewicz H, Wagner M, Fuchs A, van der Leeden C, et al. Is function in instrumental activities of daily living a useful feature in predicting A lzheimer's disease dementia in subjective cognitive decline? Int J Geriatr Psychiatry 2019; 34: 193-203.

56. Sampaio A, Marques-Aleixo I, Seabra A, Mota J, Marques E, Carvalho J. Physical fitness in institutionalized older adults with dementia: association with cognition, functional capacity and quality of life. Aging Clin Exp Res 2020; 32: 2329-2338.

57. Lim SC, Gan WY, Chan YM. The effects of socio-demographic characteristics, nutritional status, physical activity and physical function on cognitive function of community-dwelling older adults in the Klang Valley, Malaysia. Malaysian Journal of Medicine and Health Sciences 2020; 16 (Suppl 6): 163-169.

58. Arvanitakis Z, Capuano AW, Bennett DA, Barnes LL. Body Mass Index and Decline in Cognitive Function in Older Black and White Persons. J Gerontol A Biol Sci Med Sci 2018; 73: 198-203.

59. Chavarro-Carvajal D, Reyes-Ortiz C, Samper-Ternent R, Arciniegas AJ, Gutierrez CC. Nutritional assessment and factors associated to malnutrition in older adults: a cross-sectional study in Bogota, Colombia. J Aging Health 2015; 27: 304-19.

60. Yu W, Yu W, Liu X, Wan T, Chen C, Xiong L, et al. Associations of cognitive condition with nutritional status in an elderly population: an analysis based on a 7-year database in Chongqing, the Southwest of China. BMC Geriatr 2020; 1-22.

61. World Health Organization. Age-Friendly Primary Health Care Centres Toolkit. [Updated 2008. 2020 Accessed October 20]. Available from URL: https://www.who. int/ageing/publications/upcoming_publications/en/ 